\title{
A cyclic nano-reactor achieving enhanced photodynamic tumor therapy by reversing multiple resistances
}

Peng Liu ${ }^{1}$, Yanbin Zhou ${ }^{1}$, Xinyi Shi ${ }^{1}$, Yu Yuan ${ }^{1}$, Ying Peng ${ }^{1}$, Surong Hua ${ }^{3}$, Qiange Luo ${ }^{1}$, Jinsong Ding ${ }^{1}$, Yong $\mathrm{Li}^{2^{*}}$ and Wenhu Zhou ${ }^{* *}$

\begin{abstract}
Background: Photodynamic therapy (PDT) is a clinically implemented modality to combat malignant tumor, while its efficacy is largely limited by several resistance factors from tumor microenvironment (TME), such as hypoxia, antioxidant systems, and ATP-dependent tumor adaptive resistances. The aim of this work is to construct a multifunctional nanoplatform to remodel multiple resistant TME for enhanced PDT.
\end{abstract}

Results: Here, a targeting nano-reactor was facilely constructed to reverse the multiple resistances of PDT by incorporating glucose oxidase (GOx) and chlorin e6 (Ce6) into poly (D, L-lactic-co-glycolic acid) (PLGA)/ metal-organic framework (MOF) core-shell nanoassembly, with surface deposition of hyaluronic acid (HA) stabilized $\mathrm{MnO}_{2}$. The nano-reactor could selectively target tumor cells by virtue of surface HA modification, and once internalization, a few reactions were initiated to modulate TME. Glucose was consumed by GOx to inhibit ATP generation, and the produced $\mathrm{H}_{2} \mathrm{O}_{2}$ was catalyzed by $\mathrm{MnO}_{2}$ to generate $\mathrm{O}_{2}$ for tumor hypoxia alleviation and photodynamic sensitization, and glutathione (GSH) was also effectively depleted by $\mathrm{MnO}_{2}$ to suppress the tumor antioxidant defense. Consequently, the nano-reactor achieved robust PDT with amplified tumor therapy via intravenous injection.

Conclusions: This nano-reactor offers a multifunctional nanoplatform to sensitize TME-limited tumor treatment means via reversing multiple resistances.

Keywords: Nanomedicine, Targeting, Tumor hypoxia, Drug resistance, Starvation therapy, GSH depletion, Oxygenation, Metal-organic-frameworks

\section{Background}

Photodynamic therapy (PDT) has gain tremendous fundamental and translational attention for tumor therapy, owing to its advantages of low systemic toxicity, noninvasive, spatial and temporal controllable activation $[1$, 2]. During the process of PDT, the photosensitizers (PSs)

\footnotetext{
*Correspondence: liyongpuwaike@163.com; zhouwenhuyaoji@163.com ${ }^{1}$ Xiangya School of Pharmaceutical Sciences, Central South University, Changsha 410013, Hunan, China

2 Department of Pediatric Surgery, Hunan Children's Hospital, Changsha 410004, Hunan, China

Full list of author information is available at the end of the article
}

are activated by light to convert oxygen into toxic reactive oxygen species (ROS), which bind and dis-functionalize some bio-macromolecules in tumor cells, such as DNA and lipid, resulting in cell apoptosis or necrosis, immune responses and microvascular damage [3-7]. Such process is highly efficient to kill cancer at cellular level, and some PSs, such as verteporfin, 5-ALA and temoporfin, have been demonstrated as promising candidate for clinical translation $[8,9]$. However, while PDT has been accepted for several types of cancer in clinic [10], its widespread implementation is still hindered by various biological limitations. Aside from the inherent barrier of light penetration that can be partially addressed by deep PDT

c) The Author(s) 2021. This article is licensed under a Creative Commons Attribution 4.0 International License, which permits use, sharing, adaptation, distribution and reproduction in any medium or format, as long as you give appropriate credit to the original author(s) and the source, provide a link to the Creative Commons licence, and indicate if changes were made. The images or other third party material in this article are included in the article's Creative Commons licence, unless indicated otherwise in a credit line to the material. If material is not included in the article's Creative Commons licence and your intended use is not permitted by statutory regulation or exceeds the permitted use, you will need to obtain permission directly from the copyright holder. To view a copy of this licence, visit http://creativeco mmons.org/licenses/by/4.0/. The Creative Commons Public Domain Dedication waiver (http://creativecommons.org/publicdomain/ zero/1.0/) applies to the data made available in this article, unless otherwise stated in a credit line to the data. 
techniques, tumor resistances are the main mechanism to weaken the efficacy of PDT [11].

Tumor cells can resist PDT by different pathways due to the complexity of tumor microenvironment (TME), in which the most well-known feature is hypoxia. Hypoxic cells are $\sim$ threefold more resistant to ROS damage than aerobic cells [12], and more importantly, hypoxic environment could directly decrease the PDT efficacy by blocking the oxygen supply $[13,14]$. What's more, the PDT process would further aggravate tumor hypoxia through oxygen consumption and vascular damage, which activates hypoxia inducible factor- $1 \alpha$ (HIF-1 $\alpha)$ survival pathway, thus causing PDT resistance $[15,16]$. At the same time, cancer cells are equipped with antioxidant defense systems, in which the most abundant one is glutathione (GSH), to scavenge the ROS and thus counteract ROS-mediated injury [17-19]. In addition, tumor cells could generate adaptive resistance toward PDT through upregulation of drug efflux proteins, heat shock proteins (HSPs), and DNA repair proteins [20-22]. It has been reported that numerous drug efflux proteins, such as P-glycoprotein (P-gp), and ATP-binding cassette super-family $\mathrm{G}$ member 2 (ABCG2), have been implicated in PDT resistance via pumping out PSs before their action [23].

To reverse PDT resistance, various nano-systems capable of modulating TME have been developed. For example, replenishment of oxygen is a commonly employed strategy to alleviate hypoxia, which can be achieved by either oxygen delivery (using hemoglobin or perfluorocarbons) or endogenous oxygen generation (through catalytic converting tumor abundant $\mathrm{H}_{2} \mathrm{O}_{2}$ into $\mathrm{O}_{2}$ ) [24-26]. Oxygen generation can be further boosted by cascade equipping the nano-system with glucose oxidase (GOx) to supplement $\mathrm{H}_{2} \mathrm{O}_{2}$ substrate [27]. To augment PDT efficacy, several nano-vehicles were also designed to suppress the tumor antioxidant defense and restore the ROS damage effect of PDT via antioxidants depletion [28, 29]. Moreover, inhibition of ATP was reported to sensitize PDT by inhibiting drug efflux and aggravating PDTinduced DNA damage [30, 31]. Ideally, simultaneous remodeling various TME to alleviate multiple biological resistances is preferred for optimized PDT, considering the cunning nature of cancer. Unfortunately, the development of nanoparticles with multifunctionalities often requires sophisticated materials design and complicated preparation procedure, thus imposing the difficult of cost-effective, reproducible, and scalable production.

To tackle this, we designed and facilely prepared a core-shell nano-reactor for enhanced PDT via simultaneous oxygenation, antioxidant suppression, and ATP depletion (Scheme 1). Tannic acid (TA), ferric iron $\left(\mathrm{Fe}^{3+}\right)$ and poly (D, L-lactic-co-glycolic acid) (PLGA) were assembled into core-shell structure via hydrophobic, $\pi-\pi$ staking, and electrostatic interactions [32-34], in which chlorin e6 (Ce6, a widely used PS) and GOx were

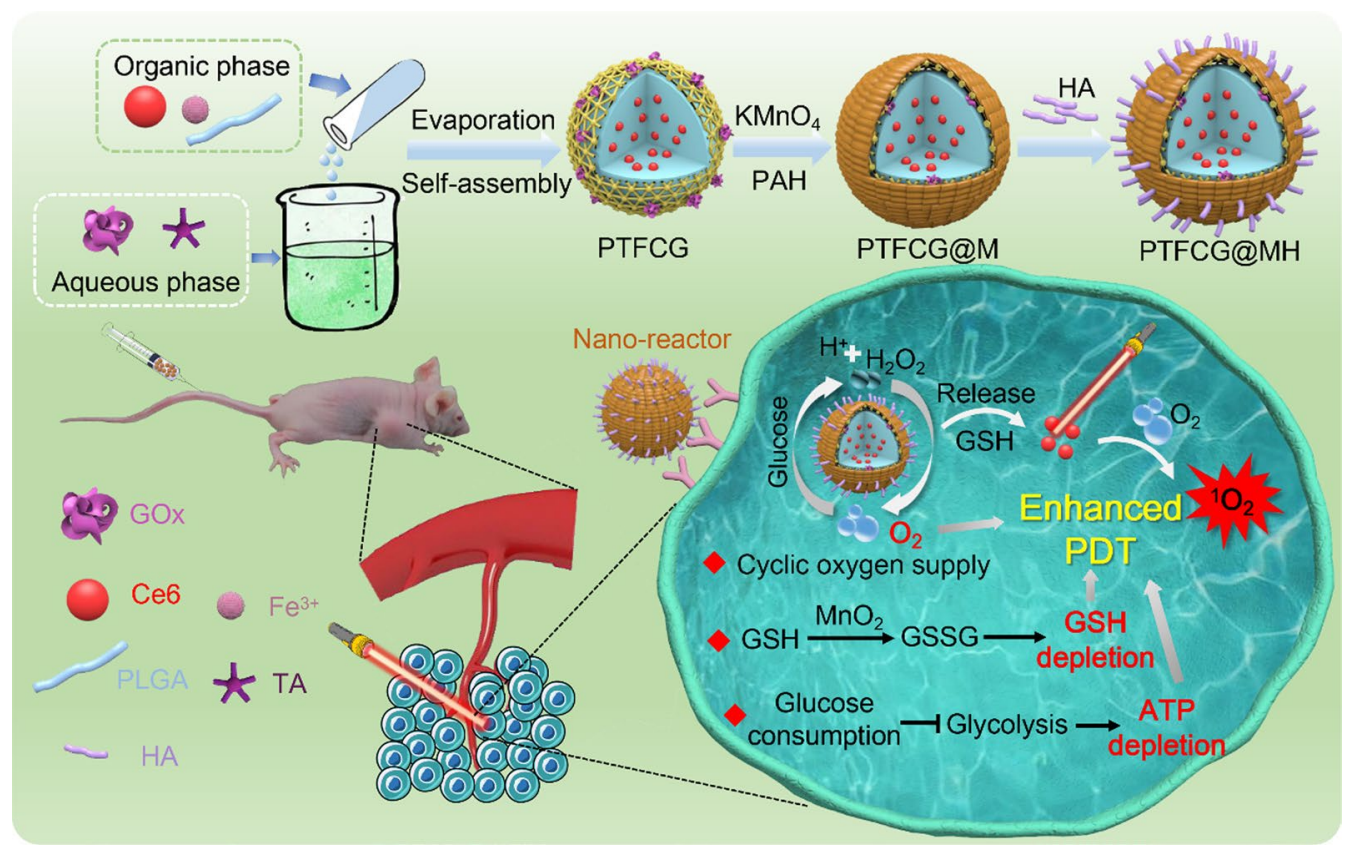

Scheme 1 Schematic illustration the preparation of core-sell nano-reactor, and its targeted delivery in vivo for enhanced PDT against tumor by reversing multiple resistances 
co-loaded. $\mathrm{MnO}_{2}$ was deposited on particle surface and stabilized by hyaluronic acid (HA) through layer-by-layer electrostatic adsorption. In our system, the $\mathrm{MnO}_{2}$ played dual roles of self-oxygen supply and GSH depletion via its catalase-mimic activity and oxidbillity, respectively. The GOx boosted the oxygenation by in-situ generation of $\mathrm{H}_{2} \mathrm{O}_{2}$, and its capability of glucose consumption blocked the energy supply to decrease ATP generation. All these functions collectively remodeled the TME from different aspect to sensitize PDT efficacy, which has been demonstrated by solution, in vitro and in vivo experimental results. The nanosystem could passively accumulate into tumor, actively internalize tumor cells via HA-mediated targeting, and impose potent PDT effect via reversing multiple resistances.

\section{Materials and methods Materials}

Chlorin e6 (Ce6) and Nile red (NR) were obtained from Frontier Scientific, Inc. (Utah, USA). PLGA (Mw: 20 kDa) was purchased from Daigang Biomaterial Co., Ltd. (Jinan, China). Hyaluronic acid (HA, $7 \mathrm{kDa}$ ) was purchased from Lifecore Biomedical Company (MN, USA). Poly (allylamine hydrochloride) (PAH), tannic acid (TA), glucose oxidase (GOx), singlet oxygen sensor green (SOSG), and 3-(4, 5-dimethylthiazol-2-yl)-2, 5-diphenyl tetrazolium bromide (MTT) were provided by Sigma-Aldrich (Saint Louis, MO, USA). Live \& dead viability/cytotoxicity assay kit was obtained by Invitrogen (NY, USA). Ellman's reagent and 4', 6-diamidino-2-phenylindole (DAPI) were provided by Solarbio Biotech, Co., Ltd. (Bei- was stirred at $30{ }^{\circ} \mathrm{C}$ for $3 \mathrm{~h}$ to evaporate acetone. The PTFCG was separated by centrifugation $(16,000 \mathrm{rpm}$, $25 \mathrm{~min}$ ) and washed by deionized water. To prepare PTFCG@MH, $50 \mu \mathrm{L}$ PAH $(20 \mathrm{mg} / \mathrm{mL})$ was mixed with $1 \mathrm{~mL}$ PTFCG solution and mild stirred for $30 \mathrm{~min}$. Then, $25 \mu \mathrm{L}$ potassium permanganate $(10 \mathrm{mg} / \mathrm{mL})$ was added and stirred for another $1 \mathrm{~h}$. After centrifugation $(16,000 \mathrm{rpm}$ for $25 \mathrm{~min})$ and washing with deionized water, the PTFCG@M was obtained. Finally, $500 \mu \mathrm{L}$ HA $(20 \mathrm{mg} / \mathrm{mL})$ was introduced into $1 \mathrm{~mL}$ of PTFCG@M solution and stirred for $1 \mathrm{~h}$. Excess HA was removed by centrifugation (16,000 rpm, 25 min), and PTFCG@MH was collected.

\section{Characterizations of PTFCG@MH}

The particle sizes and $\zeta$ potential of PTFCG, PTFCG@M and PTFCG@MH were measured by a Malvern Zeta Sizer Nano series (Malvern, UK) at $25^{\circ} \mathrm{C}$. The morphologies and element content were investigated by TEM-EDS (Titan G2 60-300, FEI, USA). For TEM-EDS analysis, the PTFCG or PTFCG@MH solution was dropped onto carbon film-coated copper grid and observed under TEM-EDS instrument. The UV-vis absorption spectra were carried out on UV-visible spectrophotometer (Shimadzu, Japan). The fluorescence spectra were collected using FL-2700 spectrofluorometer (HITACHIH). The Ce6 concentration was determined by the UV-visible spectra spectrophotometer at $640 \mathrm{~nm}$. The loading amount of GOx was estimated using bicinchoninic acid (BCA) protein assay (Beyotime) and the protocol was provided by the supplier. The drug loading (DL) of Ce6 and GOx in the PTFCG@MH was calculated as follows:

DL = amount of loaded drug in the PTFCG@MH / weight of PTFCG@MH $(\mu \mathrm{g} / \mathrm{mg})$.

jing, China). Ferric chloride hexahydrate $\left(\mathrm{FeCl}_{3} \cdot 6 \mathrm{H}_{2} \mathrm{O}\right)$, $\mathrm{N}$-acetylcysteine (NAC) and 2' 7'-dichlorofluorescin diacetate (DCFDA) were obtained from Sinopharm Chemical Reagent Co., Ltd (Shanghai, China). DMEM medium, fetal bovine serum, streptomycin/penicillin and Trypsin-EDTA were provided by GIBCO (NY, USA). The 3,5-dinitrosalicylic acid (DNS) reagent was purchased from Coolaber Biotech, Co., Ltd. (Beijing, China). ROS-ID hypoxia detection kit was provided by Enzo Life Sciences Inc. (NY, USA).

\section{Preparation of PTFCG@MH}

$\mathrm{Ce} 6, \mathrm{FeCl}_{3}$ and PLGA were mixed in acetone at a concentration of $400 \mu \mathrm{g} / \mathrm{mL}, 400 \mu \mathrm{g} / \mathrm{mL}$ and $2 \mathrm{mg} / \mathrm{mL}$, respectively. Then, $1 \mathrm{~mL}$ of such mixture was added dropwise to $5 \mathrm{~mL}$ aqueous solution containing $320 \mu \mathrm{g} / \mathrm{mL}$ TA and $20 \mu \mathrm{g} / \mathrm{mL}$ GOx under constant sonication. The solution

\section{In vitro release of $\mathrm{Ce} 6$}

The PTFCG@MH solution $([\mathrm{Ce} 6]=200 \mu \mathrm{g} / \mathrm{mL})$ was dispersed in $5 \mathrm{~mL}$ of various dissolution media $(10 \mathrm{mM}$ PBS buffer, $10 \mathrm{mM}$ PBS buffer containing $10 \mathrm{mM}$ GSH). The mixtures were shaken gently in a shaking incubator at $37^{\circ} \mathrm{C}$. At predetermined time intervals $(0,1,2,4,8$, $12 \mathrm{~h}), 0.5 \mathrm{~mL}$ of samples were withdrawn and centrifuged $(16,000 \mathrm{rpm}, 25 \mathrm{~min})$. The supernatant was collected, and the amount of Ce6 was quantified by UV absorbance quantification $(\lambda=640 \mathrm{~nm})$.

\section{Cyclic reaction of PTFCG@MH}

The catalytic activity of GOx was determined by measuring the glucose consumption and $\mathrm{pH}$ change in presence of glucose. For the glucose consumption, the PTF@MH or PTFCG@MH solution $([\mathrm{GOx}]=4 \mu \mathrm{g} / \mathrm{mL})$ was mixed with glucose $(10 \mathrm{mM})$ in the presence or absence of $\mathrm{H}_{2} \mathrm{O}_{2}$ 
$(100 \mu \mathrm{M})$ at $37{ }^{\circ} \mathrm{C}$, then the glucose concentration was detected by DNS reagent (Coolaber) within $1 \mathrm{~h}$ and the protocol was provided by the supplier. For the $\mathrm{pH}$ change, the glucose $(10 \mathrm{mM})$ was added into PTFCG or PTFCG@ $\mathrm{MH}$ solution $([\mathrm{GOx}]=4 \mu \mathrm{g} / \mathrm{mL})$ at $37{ }^{\circ} \mathrm{C}$, then the $\mathrm{pH}$ value was measured by a $\mathrm{pH}$ meter (PHSJ-4F, INESA, China) within $30 \mathrm{~min}$. To monitor the oxygen generation under different acidic conditions, PTFCG@MH $([\mathrm{GOx}]=4 \mu \mathrm{g} / \mathrm{mL})$ was dispersed in $10 \mathrm{mM}$ PBS buffer $\left(\mathrm{pH} 5.0,6.0\right.$, and 7.0) containing $1 \mathrm{mM} \mathrm{H}_{2} \mathrm{O}_{2}$. At predetermined time points, the dissolved $\mathrm{O}_{2}$ was detected using the portable dissolved oxygen meter (JPBJ-609L, INESA, China). Moreover, the PTFCG or PTFCG@MH $([\mathrm{GOx}]=4 \mu \mathrm{g} / \mathrm{mL})$ was mixed with glucose $(10 \mathrm{mM})$ in the presence or absence of $\mathrm{H}_{2} \mathrm{O}_{2}(100 \mu \mathrm{M})$ and laser irradiation (ADR-1805 Laser, $100 \mathrm{~mW} / \mathrm{cm}^{2}, 635 \mathrm{~nm}$ ), then the dissolved $\mathrm{O}_{2}$ was measured within $160 \mathrm{~s}$.

\section{The ${ }^{1} \mathrm{O}_{2}$ generation analysis}

PTF@MH or PTFCG@MH $([\mathrm{Ce} 6]=1 \quad \mu \mathrm{g} / \mathrm{mL})$ was added into SOSG solution $(2.5 \mu \mathrm{M})$, followed by adding $\mathrm{H}_{2} \mathrm{O}_{2}(10 \mathrm{mM})$. Then, a continuous laser $\left(100 \mathrm{~mW} / \mathrm{cm}^{2}\right.$, $635 \mathrm{~nm})$ was performed at predetermined time points $(0,1,2,4,6,8,10 \mathrm{~min})$, and fluorescence intensity was detected immediately by fluorescence spectroscopy $(\mathrm{Ex}=490 \mathrm{~nm}, \mathrm{Em}=525 \mathrm{~nm})$.

\section{Cell culture}

MDA-MB-231 and HUVEC cells were cultured under a humidified atmosphere of $5 \% \mathrm{CO}_{2}$ at $37{ }^{\circ} \mathrm{C}$ using DMEM and RPMI 1640 complete medium, respectively. The complete medium contains 10\% FBS (GIBCO, USA), 1\% penicillin/streptomycin (100 U/mL, Solarbio Bioteh).

\section{Cellular uptake}

The NR-loaded nanoparticles were prepared following the method described above by replacing Ce6 with NR. The cells were seeded in Petri dish $(35 \mathrm{~mm})$ at $5 \times 10^{4}$ cells $/ \mathrm{cm}^{2}$ and cultured overnight. With or without pretreatment of free HA $(10 \mathrm{mg} / \mathrm{mL})$ for $1 \mathrm{~h}$, the cells were incubated with NR-loaded nanoparticles or free NR $([\mathrm{NR}]=2 \mu \mathrm{g} / \mathrm{mL})$ for another $2 \mathrm{~h}$. Next, the cells were washed with pre-cooled PBS and fixed with $4 \%$ paraformaldehyde. After staining by DAPI $(1 \mu \mathrm{g} / \mathrm{mL})$, the cells were imaged under confocal microscope (LSM780 NLO, Zeiss, Germany).

To study the endocytosis mechanism, the cells were seeded in 6-well culture plate $\left(2 \times 10^{5}\right.$ cells/well). After pretreating with chlorpromazine $(10 \mu \mathrm{g} / \mathrm{mL})$, nystatin $(15 \mu \mathrm{g} / \mathrm{mL})$ or colchicine $(5 \mu \mathrm{g} / \mathrm{mL})$ for $1 \mathrm{~h}$, the cells were incubated with NR-loaded nanoparticles $([\mathrm{NR}]=2 \mu \mathrm{g} /$ $\mathrm{mL}$ ) for $2 \mathrm{~h}$. Then, the cells were washed with pre-cooled
PBS, digested by Trypsin-EDTA and analyzed using flow cytometry (FACSVerse, BD, USA).

\section{Intracellular $\mathrm{O}_{2}$ consumption and ROS detection}

ROS-ID and DCFDA were used to detect the intracellular $\mathrm{O}_{2}$ consumption and ROS generation inside cells. The MDA-MB-231 cells were seeded in 24-well culture plate $\left(10^{5}\right.$ cells/well $)$ and cultured overnight. After sealing by liquid paraffin, the cells were incubated with PTFCG@ MH, PTF@MH, PTFCG, or free Ce6 $([\mathrm{Ce} 6]=1 \mu \mathrm{g} / \mathrm{mL})$ for $2 \mathrm{~h}$. Then, laser irradiation $\left(635 \mathrm{~nm}, 100 \mathrm{~mW} / \mathrm{cm}^{2}\right)$ was applied for $2 \mathrm{~min}$. With PBS washing for three times, the mixture of ROS-ID $(0.5 \mu \mathrm{M})$ and DCFDA $(10 \mu \mathrm{M})$ was added into each group for 30 min further incubation. After washing with pre-cooled PBS, fluorescence inside cells was observed by fluorescence imaging system (NIKON, Ti-S, Japan).

\section{Intracellular ATP and GSH detection}

MDA-MB-231 cells were seeded in 12-well plate at a density of $2 \times 10^{5}$ cells per well for $12 \mathrm{~h}$ incubation. Then, various formulations with different concentrations were added for $24 \mathrm{~h}$ incubation. After that, the cells were collected and lysed using ATP lysis buffer, and ATP concentration was measured by ATP assay kit (Beyotime). Likewise, the cells were collected and lysed using the Triton-X 100 cell lysis buffer, and GSH concentration was detected by the Ellman's reagent (Solarbio). The numbers of cells were standardized by measuring total protein concentration using BCA protein assay (Beyotime).

\section{In vitro cytotoxicity studies}

MDA-MB-231 cells were seeded in a 96-well plate (5000 cells/well) for overnight incubation. The cells were treated with PTFCG or PTFCG@MH at different concentrations for $24 \mathrm{~h}$, followed by laser irradiation for $1 \mathrm{~min}\left(100 \mathrm{~mW} / \mathrm{cm}^{2}, 635 \mathrm{~nm}\right)$. After $24 \mathrm{~h}$, MTT solution $(1 \mathrm{mg} / \mathrm{mL})$ was added for another $4 \mathrm{~h}$ incubation. The medium was replaced with $100 \mu \mathrm{L}$ of DMSO. The absorbance values at $570 \mathrm{~nm}$ were recorded to calculate the cell viability. Then, the Live/Dead assay was carried out by calcein AM/propidium iodide double staining. The cells were seeded and treated as described above. After laser irradiation $\left(100 \mathrm{~mW} / \mathrm{cm}^{2}, 635 \mathrm{~nm}\right)$, the fresh medium containing calcein AM $(2 \mu \mathrm{M})$ and propidium iodide $(8 \mu \mathrm{M})$ was added for 20 min incubation. Finally, the cells were imaged by fluorescence imaging system (NIKON, Ti-S, Japan).

\section{In vivo/ex vivo fluorescence imaging}

Healthy female Balb/c mice (aged 4-6 weeks) were purchased from the Laboratory Animal Center of Central South University. All experimental procedures were 
carried out in accordance with the Regulations for the Administration of Affairs Concerning Experimental Animals of China, and approved by the Ethics Committee for Research in Animal Subjects at Xiangya School of Pharmaceutical Sciences of Central South University. MDA-MB-231 tumor-bearing mice were obtained by subcutaneously injecting a cells suspension in PBS $\left(10^{6}\right.$ cells) into the right armpit of mice. When the tumor volume reached $\sim 100 \mathrm{~mm}^{3}$, the mice were treated with different formulations.

For in vivo/ex vivo imaging, the tumor-bearing mice were intravenously injected with free Ce6 or PTFCG@ $\mathrm{MH}(100 \mu \mathrm{L},[\mathrm{Ce} 6]=2.5 \mathrm{mg} / \mathrm{kg})$, and the fluorescence images were taken by an optical imaging system (IVIS Lumina, PerkinElmer, USA) at $1 \mathrm{~h}$ and $24 \mathrm{~h}$ post-injection. The mice were sacrificed at $24 \mathrm{~h}$ after injection, and the major organs were collected for ex vivo imaging. The images were analyzed using Living Imaging Software (IVIS Lumina LT, PerkinElmer, USA).

\section{In vivo antitumor study}

The tumor-bearing mice were randomly divided into 5 groups and injected intravenously with (1) PBS, (2) Ce6 + Laser, (3) PTFCG + Laser, (4) PTFCG@MH, (5) PTFCG@MH+Laser $(100 \mu \mathrm{L},[\mathrm{Ce} 6]=2.5 \mathrm{mg} / \mathrm{kg})$ at day 0 and 4 . The irradiation groups were exposed to laser $\left(100 \mathrm{~mW} / \mathrm{cm}^{2}, 635 \mathrm{~nm}\right)$ for $5 \mathrm{~min}$ at $24 \mathrm{~h}$ after injection. The tumor volume was recorded and calculated as follows: $V=\left(\right.$ length $\times$ width $\left.^{2}\right) / 2$. In addition, the body weights were also obtained. At day 14 , all the mice were sacrificed, and the tumors were collected and weighed. For histology analysis, the major organs and tumors were extracted and immersed in $4 \%$ formaldehyde, embedded in paraffin, sectioned, stained with $H \& E$ and observed by an optical microscope (Leica, German).

\section{Immunofluorescence analysis}

The expression of HIF- $1 \alpha$ protein was investigated by immunofluorescence assay. Nude mice bearing MDAMB-231 tumors were sacrificed at $48 \mathrm{~h}$ after various treatments mentioned above. Tumor tissues were collected for preparing slices of tumor frozen sections. Then, the slices were stained with HIF- $1 \alpha$ antibody (mouse polyclonal to HIF-1 $\alpha$, Abcam) at $4{ }^{\circ} \mathrm{C}$ overnight, followed by adding the secondary antibodies conjugated with FITC for $1 \mathrm{~h}$ incubation. After cell nuclei staining with Hoechst 33,258 for $20 \mathrm{~min}$, the tumor sections were imaged by confocal fluorescence microscope (LSM780 NLO, Zeiss, Germany).

\section{Statistical analysis}

Data were presented as mean \pm SD. Analysis was performed using Graphpad Prism 5 software. One-way
ANOVA analysis of variance was conducted to determine the statistical significance of various groups. $P$ values $<0.05$ was regarded as statistically significant.

\section{Results and discussion}

\section{Nanoparticles preparation and characterization}

The GOx and Ce6 were co-loaded into nanocomposites (PTFCG) using a solvent exchange and evaporation method (Scheme 1), in which the ethanol solution (containing Ce6, PLGA and $\mathrm{FeCl}_{3}$ ) was dropwise added into the aqueous phase (with TA and GOx). During organic evaporation, the TA-Fe metal-organic frameworks (MOFs) were coated on the surface of hydrophobic PLGA nano-core for particle stabilization, and the resulting PTFCG displayed a dynamic diameter of $\sim 175 \mathrm{~nm}$ (Fig. 1A, Additional file 1: Figure S1) with $\zeta$ potential of $-33.4 \mathrm{mV}$ (Fig. 1C). From the TEM image, the PTFCG displayed a roughly spherical morphology with an obvious core-shell structure (inset in Fig. 1A). To further deposit $\mathrm{MnO}_{2}$ on particle surface, a PAH solution was added, followed by adding $\mathrm{KMnO}_{4}$, allowing for in-situ growth of $\mathrm{MnO}_{2}$ on nanoparticle surface to yield PTFCG@M. Compared with PTFCG, the $\zeta$ potential of PTFCG@M was reversed to positive $(+17.3 \mathrm{mV})$ (Fig. 1C), which allowed for the subsequent HA coating via electrostatic attraction (termed PTFCG@MH). The successful HA modification was evidenced by the decrease of particle charge to negative $(-21.7 \mathrm{mV})$ (Fig. 1C), which is beneficial for enhanced colloidal stability. [35] The resulting PTFCG@MH nanoparticles displayed a dynamic diameter of $\sim 205 \mathrm{~nm}$ (Fig. 1B), while the size measured by TEM was $\sim 160 \mathrm{~nm}$ (inset in Fig. 1B, Additional file 1: Figure S2). It is reasonable as DLS measurement would distort the particle size being observed due to the particle surface hydration. Importantly, the HA modification not only significantly increased the colloidal stability (Additional file 1: Figure S3), [36] but also rendered the nanoparticles with tumor targetability (vide infra).

According to the UV-vis absorbance spectra, PTFCG had characteristic Ce6 peaks at $404 \mathrm{~nm}$ and $640 \mathrm{~nm}$, indicating the successful Ce6 loading (Fig. 1D). For PTFCG@ $\mathrm{MH}$, a wide absorbance band in the range from 250$400 \mathrm{~nm}$ appeared, which was ascribed to the $\mathrm{MnO}_{2}$. To confirm the $\mathrm{MnO}_{2}$ coating, the energy dispersive X-Ray spectroscopy (EDS) was conducted, and a high Mn element content ( 6\%) was observed (Fig. 1E). The drug loading (DL) for $\mathrm{Ce} 6$ and GOx was measured to be 108.4 $\mu \mathrm{g}$ and $24.6 \mu \mathrm{g}$ per mg of PTFCG@MH, respectively. Interestingly, after encapsulation into nanoparticles, the intrinsic fluorescence of $\mathrm{Ce} 6$ was significantly quenched, especially for PTFCG@MH (Additional file 1: Figure S4). However, such quenched fluorescence can be 

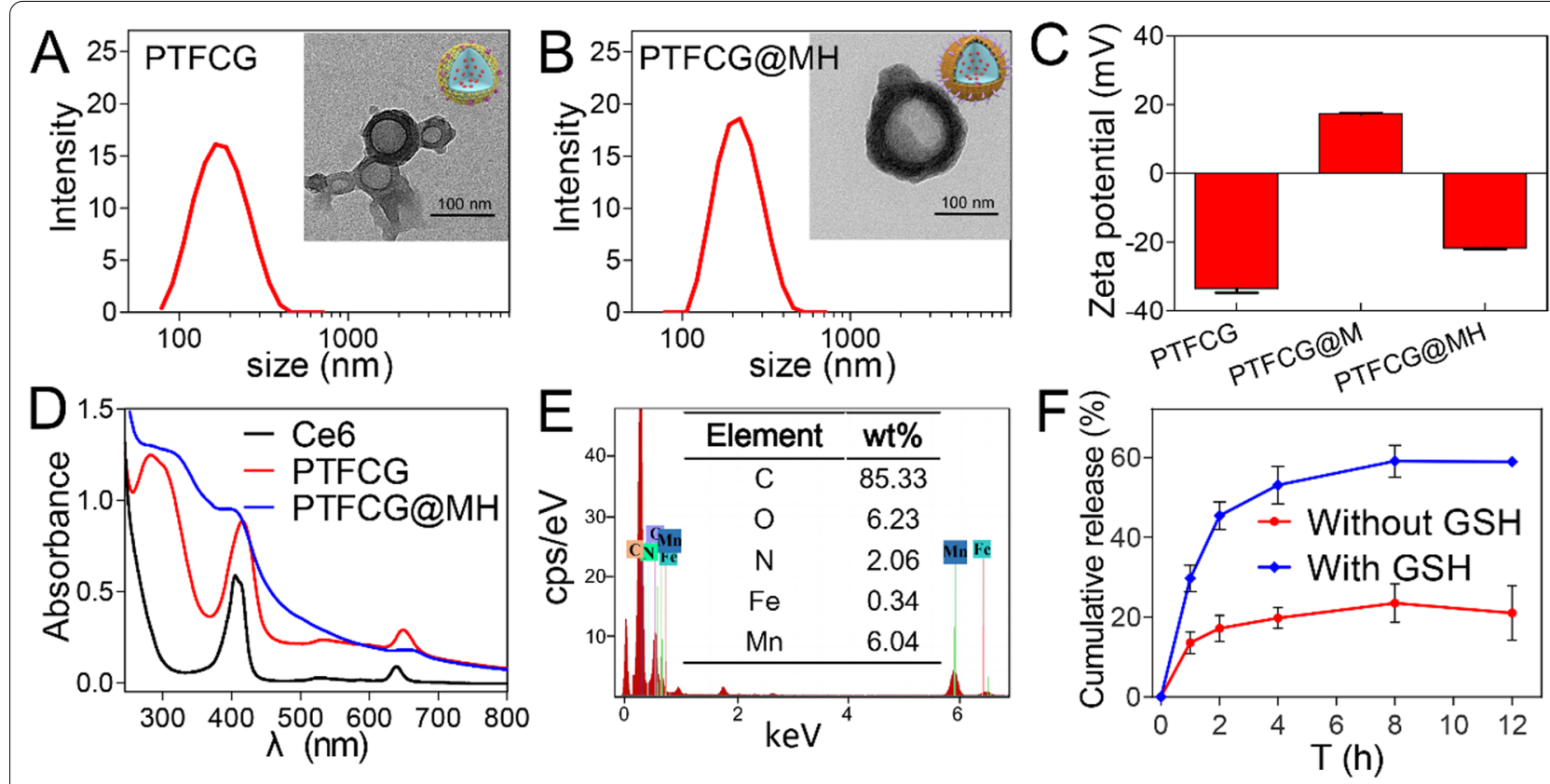

Fig. 1 Dynamic sizes and TEM images of A PTFCG and B PTFCG@MH. C The $\zeta$ potential of PTFCG, PTFCG@M and PTFCG@MH. D UV-vis absorbance spectra of Ce6, PTFCG and PTFCG@MH. E Energy dispersive X-Ray spectroscopy (EDS) analysis of PTFCG@MH. F In vitro Ce6 release from PTFCG@MH with or without addition of GSH (10 mM)

largely recovered upon addition of GSH, indicating GSHresponsive release of Ce6. To confirm this, Ce6 release behavior from PTFCG@MH was investigated (Fig. 1F). In absence of GSH, the Ce6 showed $20 \%$ accumulative release, while a burst drug release was observed after adding GSH, with $\sim 60 \%$ Ce6 release within 8 h. Therefore, such nanosystem showed a triggered activation of photodynamic activity in response to intracellular stimulus, thus minimizing the potential phototoxicity of $\mathrm{Ce} 6$ during in vivo delivery.

\section{A cyclic reaction nano-reactor}

As illustrated in Fig. 2A, our nanosystem was designed with a few cyclic reactions to enhance the Ce6-based PDT. GOx consumes glucose (Glu) to block the energy (ATP) supply, and the concomitantly produced $\mathrm{H}_{2} \mathrm{O}_{2}$ is decomposed by the catalase-mimic $\mathrm{MnO}_{2}$ to generate $\mathrm{O}_{2}$, which in turn boosts the ${ }^{1} \mathrm{O}_{2}$ production under laser illumination. To demonstrate this concept, each reaction was tested individually.

The catalytic activity of GOx was first measured by monitoring the glucose consumption (Fig. 2B). After 60 min incubation, PTFCG@MH decreased the glucose level by $34 \%$, while the nanoparticles without GOx loading (termed PTF@MH) did not show any glucose consumption. Therefore, GOx maintained its catalytic activity after being loaded into nanoparticles. Moreover, the glucose depletion of PTFCG@MH was further strengthened after adding $\mathrm{H}_{2} \mathrm{O}_{2}$, which can be ascribed to the decomposition of $\mathrm{H}_{2} \mathrm{O}_{2}$ by PTFCG@MH to supply $\mathrm{O}_{2}$. Michaelis-Menten constant $\left(\mathrm{K}_{\mathrm{M}}\right)$ was calculated to quantify the reaction kinetics, and the $\mathrm{K}_{\mathrm{M}}$ value of PTFCG@MH $+\mathrm{H}_{2} \mathrm{O}_{2}$ and PTFCG@MH turned out to be 6.35 and $10.02 \mathrm{mM}$ (Additional file 1: Figure S5), indicating the promoted glucose consumption by $\mathrm{H}_{2} \mathrm{O}_{2}$. The activity of GOx can also be monitored by the $\mathrm{pH}$ decrease due to the generation of gluconic acid byproduct. Upon addition of glucose, both PTFCG and PTFCG@MH showed a gradual $\mathrm{pH}$ decrease over time (Fig. 2C). Notably, PTFCG@MH exhibited a relative lower pH decrease rate than that of PTFCG. This is likely due to that the surface deposited $\mathrm{MnO}_{2}$ impeded accessibility of glucose into GOx-loaded nanocore. In addition, the $\mathrm{MnO}_{2}$ could neutralize $\mathrm{H}^{+}$to slow down $\mathrm{pH}$ decrease rate.

Next, the catalase-mimic activity of $\mathrm{MnO}_{2}$ was tested by monitoring $\mathrm{O}_{2}$ production in presence of $\mathrm{H}_{2} \mathrm{O}_{2}$ (Fig. 2D). As a control, the PTFCG@MH alone did not show any $\mathrm{O}_{2}$ generation. However, a rapid increase of the dissolved $\mathrm{O}_{2}$ was observed upon addition of $\mathrm{H}_{2} \mathrm{O}_{2}$. We also studied the effect of $\mathrm{pH}$, and a marginal increase of catalytic rate was seen with the decrease of $\mathrm{pH}$ from 7.0 to 5.0. Overall, the catalytic efficiency was relatively higher under acidic tumor microenvironment than physiological conditions.

After confirming the single catalytic reaction of GOx and $\mathrm{MnO}_{2}$, we next explored the catalytic circulation by 


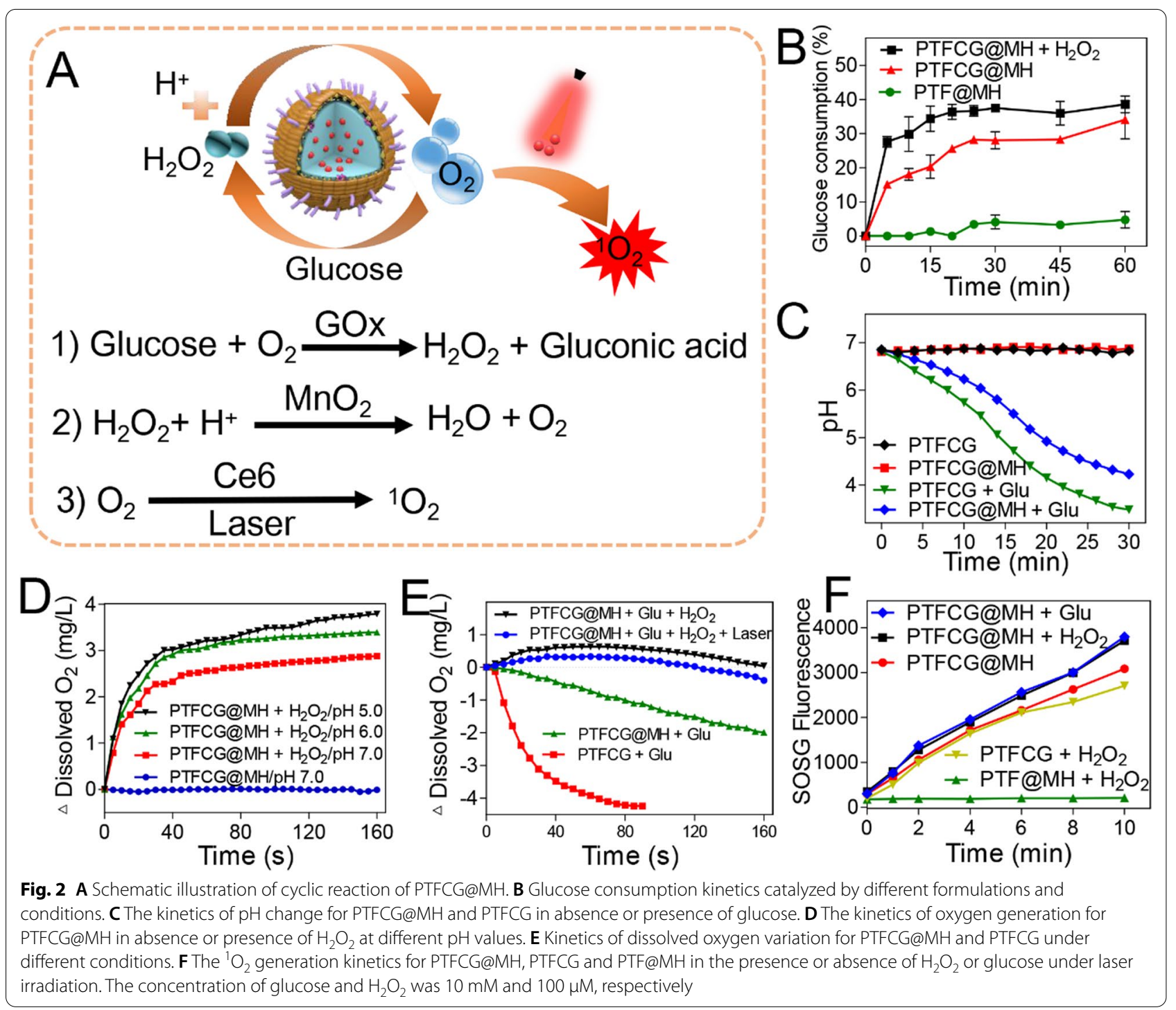

measuring the oxygen variation (Fig. 2E). For PTFCG, the dissolved $\mathrm{O}_{2}$ was quickly decreased within $100 \mathrm{~s}$ upon addition of glucose. For the PTFCG@MH, by contrast, the $\mathrm{O}_{2}$ consumption rate significantly lessened due to the self-oxygen generation activity of $\mathrm{MnO}_{2}$, demonstrating the cyclic oxygen supply. Moreover, the $\mathrm{O}_{2}$ balance was achieved upon further addition of $100 \mu \mathrm{M} \mathrm{H}_{2} \mathrm{O}_{2}$ (which mimics the tumor microenvironment) [37], and such $\mathrm{O}_{2}$ generation efficiency is strong enough to support the PDT (Fig. 2E, blue trace).

With cyclic oxygen supply, we next explored the enhanced PDT effect by measuring the single oxygen $\left({ }^{1} \mathrm{O}_{2}\right)$ generation using singlet oxygen sensor green (SOSG) as a fluorescent indicator (Fig. 2F). In presence of $\mathrm{H}_{2} \mathrm{O}_{2}$, the production of ${ }^{1} \mathrm{O}_{2}$ was obviously increased for PTFCG@MH, and the addition of glucose could also strengthen the PDT effect. As a control, the PTFCG group showed lower ${ }^{1} \mathrm{O}_{2}$ generation due to the lack of oxygen supply. All these results demonstrated the capability of cyclic nano-reactor for boosting PDT effect of Ce6.

\section{Cellular uptake}

We next tested the intracellular performance of the nanosystem by using MDA-MB-231 cancer cells. To track the intracellular delivery, nanoparticles were labeled with a red fluorescent Nile red (NR), and the cell nuclei were stained blue by DAPI for localization (Fig. 3A). From confocal laser scanning microscopy (CLSM) images, a weak red signal was observed when the cells were treated with free NR, while the fluorescence was significantly intensified for nanoparticles. From the merged image, the 


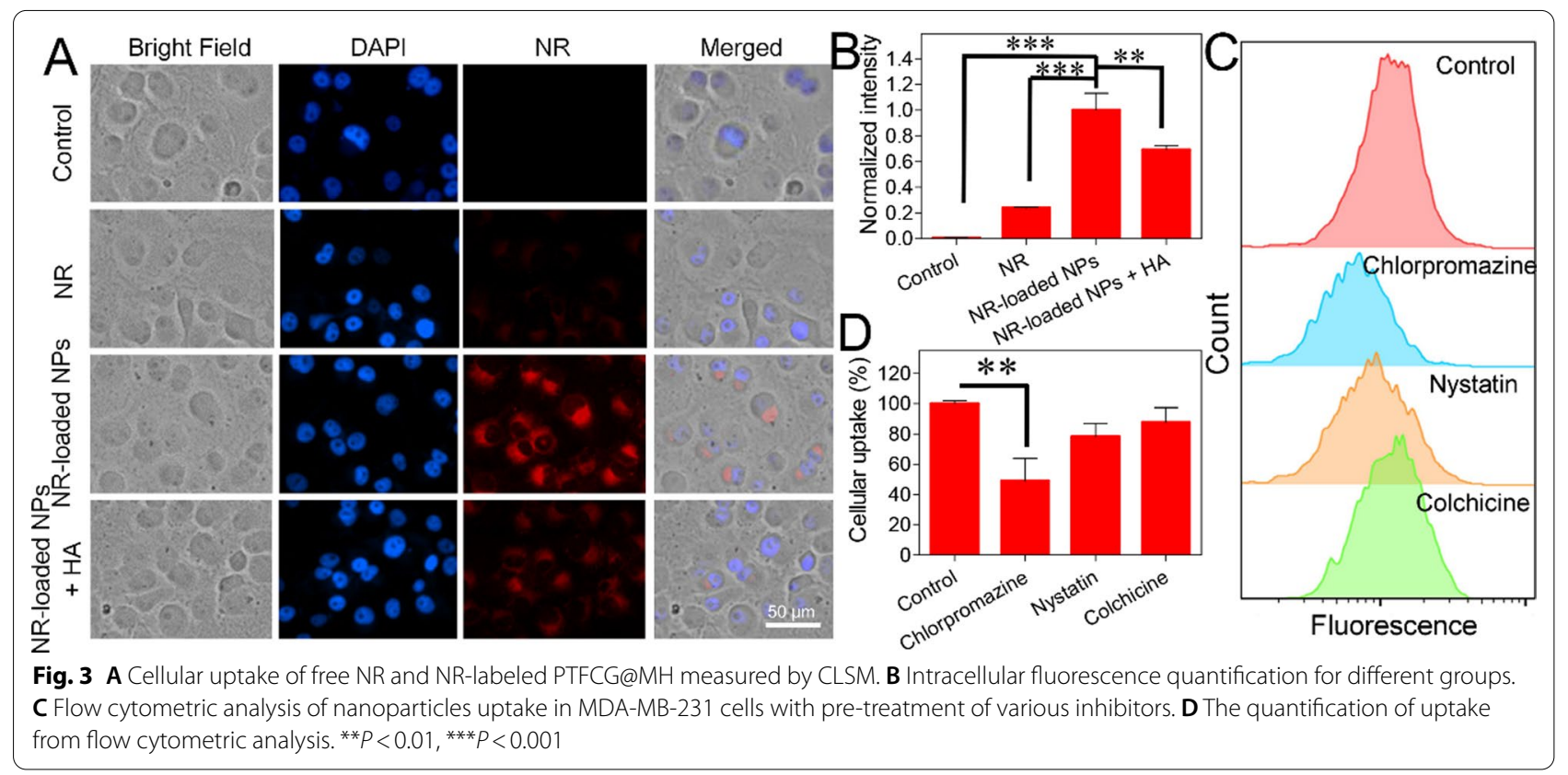

fluorescence of nanoparticles mainly distributed in the cytoplasm, indicating endocytosis pathway for internalization. To demonstrate tumor targetability of such surface HA modified nanosystem, the cells were pretreated with free HA to saturate the CD44 binding, and in this case the intracellular nanoparticles signal decreased obviously. We also quantified the contribution of HA-mediated internalization by measuring the intensity of each treatment, where the uptake was significantly decreased upon free HA pre-treatment (Fig. 3B). Using normal human umbilical vein endothelial cells (HUVEC) as control, the results further demonstrated the targetability of the nanoparticles towards tumor cells with significantly higher fluorescence (Additional file 1: Figure S6). These results confirmed that our nanosystem was able to selectively recognize tumor cells via CD44 receptor for targeting delivery. To further explore the delivery mechanism, various endocytosis inhibitors were employed, including chlorpromazine, nystatin and colchicine, which blocks clathrin-mediated endocytosis, caveolae-mediated endocytosis and micropinocytosis, respectively. Among then, chlorpromazine has the most significant impact on nanoparticles uptake (Fig. 3C, D), indicating the main contribution of clathrin-mediated endocytosis.

\section{Enhanced anti-tumor efficacy via hypoxia alleviation and ATP/GSH depletion}

After internalization, we next explored the intracellular functions of the nanosystem. To visualize the PDT effect, the ROS generation was probed by using 2' 7'-dichlorofluorescin diacetate (DCFDA) indicator. Interestingly, both PTFCG@MH and PTF@MH could scavenge the intracellular ROS to some extent as compared to the control, due to the catalase activity of $\mathrm{MnO}_{2}$. Upon irradiation, each Ce6-based formulation showed enhanced green fluorescence inside cells based on both fluorescent images (Fig. 4A) and quantified intensity (Fig. 4B). Notably, PTFCG@MH group emitted the strongest fluorescence, indicating the best PDT efficacy. This can partially be explained by the cyclic oxygenation of the nano-reactor for self-oxygen supply. To confirm this, we then measured the $\mathrm{O}_{2}$ balance by using a red fluorescent hypoxia detection kit. Both PTF@MH and PTFCG@ $\mathrm{MH}$ could relieve tumor hypoxia with red fluorescence decrease compared to non-treatment control (Fig. 4A, C), also attributable to self-oxygen supply of the $\mathrm{MnO}_{2}$. Upon addition of laser, the hypoxia was strongly exacerbated for free Ce6 and PTFCG groups, ascribed to PDTand GOx-based oxygen consumption. However, the PTFCG@MH group showed low hypoxia level even after laser irradiation. Therefore, such nano-reactor is robust enough to maintain oxygen balance with enhanced PDT efficacy.

Besides cyclic oxygen supply, such nano-reactor was also designed to deplete both ATP and GSH. We next tested these properties by measuring the intracellular ATP and GSH levels using ATP assay kit and Ellman's reagent, respectively. Because of catalytic glucose oxidation, free GOx could effectively decrease ATP level in a concentration dependent manner by blocking the energy supply (Fig. 4D). Likewise, the PTFCG@MH could also inhibit ATP generation, while the PTF@MH did not 


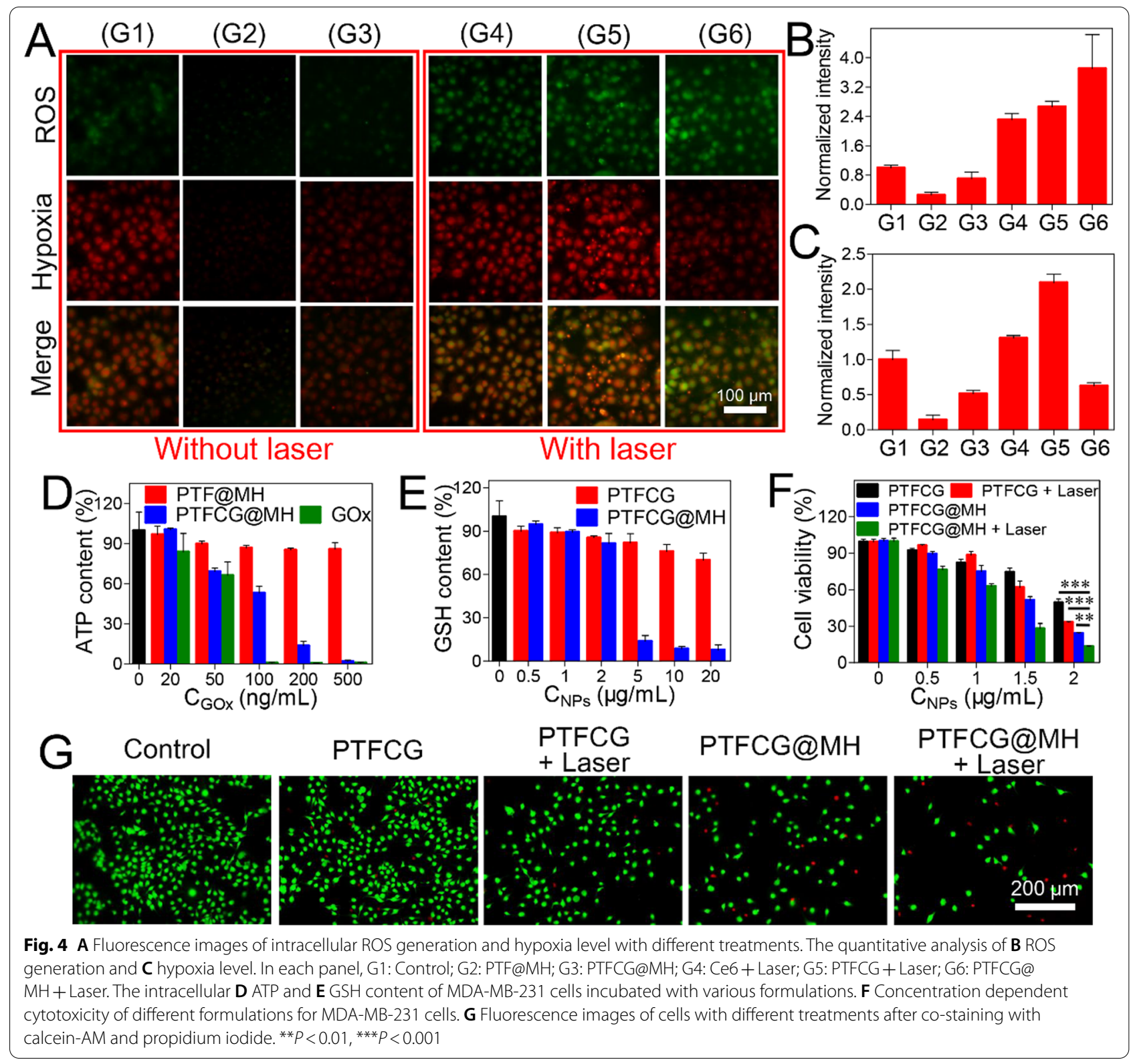

show any activity due to the absence of GOx loading. $\mathrm{MnO}_{2}$ is a well-known GSH depletor due to its capability to oxidize GSH into GSSG, accompanied by its reduction into $\mathrm{Mn}^{2+}[28,38]$. As expected, the PTFCG@MH with $\mathrm{MnO}_{2}$ doping displayed high efficient GSH depletion, with over $80 \%$ GSH decrease at $5 \mu \mathrm{g} / \mathrm{mL}$ nanoparticles (Fig. 4E). Note that ATP is the basic energy source for tumor cells to acquire treatments resistance including PDT therapy [39], and GSH could directly scavenge ${ }^{1} \mathrm{O}_{2}$ to alleviate the PDT efficacy. Therefore, with ATP and GSH dual-depletion activity, such nano-reactor was expected to enhance the PDT-based anti-tumor activity via distinct mechanisms.
Next, the in vitro cytostatic activity of nanosystem was evaluated by MTT assay. Without drugs loading, the PTF and PTF@MH showed satisfactory biocompatibility even at high concentrations (Additional file 1: Figure S7). The PTFCG, on the other hand, displayed a concentration-dependent tumor ablation activity (Fig. 4F), ascribed to the starvation therapy for ATP depletion [40]. Upon laser irradiation, the antitumor effect was further enhanced. Notably, PTFCG@MH showed significantly better efficacy than PTFCG attributable to $\mathrm{MnO}_{2}$ doping for self-oxygen circulation, GSH depletion, as well as HA modification for targeting delivery. To confirm the tumor selectivity, MTT assay was also performed on HUVEC 
cells, and as expected, higher cytotoxicity was observed for MDA-MB-231 cells (Additional file 1: Figure S8). We also explored the cell death pathway by co-staining the cells using calcein-AM (green fluorescence for live cells) and propidium iodide (red fluorescence for dead/late apoptotic cells). After different treatments, green fluorescence was weakened while the red fluorescence became intensified inside cells (Fig. 4G), indicating an apoptotic or necrotic cell death mechanism. In addition, the general anti-tumor activity for each treatment was highly consistent with the results from MTT assay.

\section{In vivo performance of the nano-reactor}

Finally, in vivo behavior of the nano-reactor was explored by using MDA-MB-231 tumor-bearing mice. By virtue of the intrinsic fluorescence of $\mathrm{Ce} 6$, the bio-distribution was visualized using a living imaging system. PTFCG@MH or free Ce6 was intravenously injected when the tumor volume reached $\sim 100 \mathrm{~mm}^{3}$. At $1 \mathrm{~h}$ post-injection, Ce6 showed red fluorescence throughout the body (Fig. 5A), indicating non-specific distribution, while most of the fluorescence was cleared after $24 \mathrm{~h}$, with major accumulation in liver. For comparison, the PTFCG@MH displayed much weaker fluorescence at $1 \mathrm{~h}$ post-injection due to the fluorescence quenching of the nanosystem, further demonstrating its advantage for decreased phototoxicity. However, the signal at tumor tissue became intensified after $24 \mathrm{~h}$ circulation (Fig. 5A, black circle), indicating the EPR effect of the nanomedicine for passive accumulation into tumor. We then quantified the results by collecting the main organs as well as tumor tissues for ex vivo fluorescence imaging (Fig. 5B). PTFCG@ $\mathrm{MH}$ exhibited $\sim 3.7$-fold higher intensity at tumor site than free Ce6, confirming the targetability of the nanosystem towards tumor tissue. Meanwhile, we also noticed considerable accumulation of nanoparticles in liver and kidneys, the main organs to sequester and eliminate nanoparticles from body, and it was also observed in many other nanomedicines $[41,42]$. Fortunately, temporal controlled activation of PDT would enable selective damage toward tumor, thus minimizing the unwanted side-effects.

To evaluate the in vivo tumor ablation activity, the tumor bearing mice were randomly divided into five groups $(n=5)$, each intravenous injection of PBS, Ce6 + Laser, PTFCG + Laser, PTFCG@ $\mathrm{MH}$, and PTFCG@MH+Laser, respectively $(100 \mu \mathrm{L}$, $[\mathrm{Ce} 6]=2.5 \mathrm{mg} / \mathrm{kg}$ ), with totally two injections (day 0

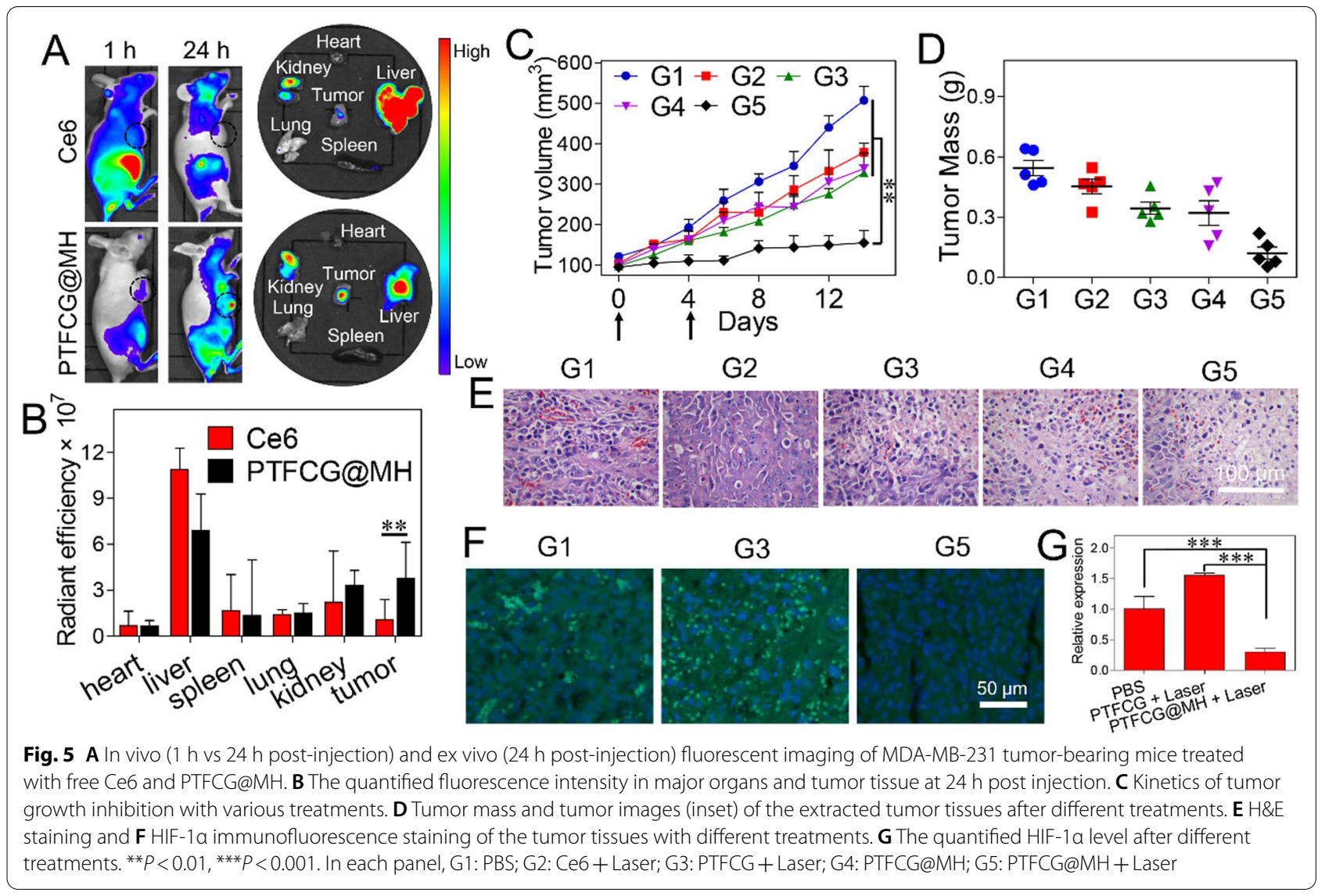


and day 4). The laser was performed at $24 \mathrm{~h}$ after injection. The therapeutic efficacy was monitored by measuring the tumor size every other day (Fig. 5C). Compared with PBS control, free Ce6 only showed marginal tumor growth inhibition, mainly due to its rapid clearance from mouse body with minimal accumulation into tumor tissue (Fig. 5A). While the nanoparticles could facilitate tumor targeting delivery of Ce6, the efficacy of PTFCG plus laser irradiation was still poor, due to the multiple resistance mechanisms of tumor against PDT therapy. For PTFCG@MH, by contrast, the growth of tumors was obviously suppressed with a strong growth-inhibitory activity $(\sim 76 \%)$. Since we only performed two dosages and the treatment was stopped at day 4 , a slight tumor recurrence was observed at day 6 . However, the overall tumor growth was significantly suppressed for PTFCG@ $\mathrm{MH}$ plus laser as compared with other treatment groups, demonstrating the superiority of the nanosystem for tumor therapy. Note that without laser irradiation, the therapeutic effect of PTFCG@MH was also rather limited, verifying that the anti-tumor activity was mainly originated from the PDT effect.

Next, the tumor tissues were extracted for a series of characterizations. Based on the tumor weight evaluations (Fig. 5D), it was clearly seen that PTFCG@MH plus laser achieved the best efficacy, in consistent with the in vivo measurement. We also explored the pathological changes by H\&E staining (Fig. 5E), in which the tumor with PTFCG@MH plus laser treatment displayed widened interstitial space, nuclear condensation, and large vacuoles, indicating the highest level of tumor apoptosis. We also evaluated the key pathological feature of tumor hypoxia by immunofluorescence staining of HIF-1 $\alpha$. The solid tumor showed a relatively high-level HIF- $1 \alpha$ expression due to its hypoxia microenvironment (Fig. 5F), and the immunofluorescence was even brighter after PTFCG treatment (with laser) because of the oxygen consumption by GOx catalysis and PDT. For comparison, the tumor hypoxia was effectively relieved after PTFCG@MH (plus laser) treatment, due to oxygenation by $\mathrm{MnO}_{2}$. From quantified results, the HIF- $1 \alpha$ level was decreased 70\% after PTFCG@MH treatment (Fig. 5G). Therefore, the PTFCG@MH could effectively modulate tumor hypoxia microenvironment and provide $\mathrm{O}_{2}$ substrate to improve PDT treatment outcome.

Finally, the biosafety of the nanosystem was examined. No obvious decrease of body weight was observed over the period of treatments (Additional file 1: Figure S9), and the H\&E staining showed no pathological change of the major organs after treatments (Additional file 1: Figure S10). These results indicate the biocompatibility of the nanosystem for in vivo applications.

\section{Conclusions}

In conclusion, an intelligent cyclic nano-reactor, PTFCG@MH, was fabricated for enhanced PDT against solid tumor. The nanostructure was well-characterized, and the cyclic reactions were explicitly demonstrated in solution, including GOx-catalyzed glucose consumption, $\mathrm{MnO}_{2}$-mediated oxygenation and GSH depletion. The surface HA modification endowed the nano-reactor with improved colloidal stability and active targetability to facilitate its accumulation into tumor after intravenous injection. After being delivered into tumor cells, PTFCG@MH boosted the PDT efficacy via simultaneous ATP/GSH suppression and self-oxygen supply, resulting in efficient tumor growth inhibition with no obvious side-effects. This cascade nano-reactor would promote the development of multifunctional nanoplatforms for improved cancer treatment by modulating unfavorable cancer microenvironment.

\begin{abstract}
Abbreviations
PDT: Photodynamic therapy; TME: Tumor microenvironment; GOx: Glucose oxidase; Ce6: Chlorin e6; PLGA: Poly (D, L-lactic-co-glycolic acid; MOF: Metalorganic framework; HA: Hyaluronic acid; GSH: Glutathione; PSs: Photosensitizers; ROS: Reactive oxygen species; HIF-1a: Hypoxia inducible factor-1a; HSPs: Heat shock proteins; P-gp: P-glycoprotein; ABCG2: ATP-binding cassette superfamily G member 2; TA: Tannic acid; NR: Nile red; PAH: Poly (allylamine hydrochloride); SOSG: Singlet oxygen sensor green; MTT: 3-(4, 5-Dimethylthiazol2-yl)-2, 5-diphenyl tetrazolium bromide; DAPI: 4', 6-Diamidino-2-phenylindole; NAC: N-acetylcysteine; DCFDA: 2' 7'-Dichlorofluorescin diacetate; EDS: Energy dispersive X-Ray spectroscopy; CLSM: Confocal laser scanning microscopy.
\end{abstract}

\section{Supplementary Information}

The online version contains supplementary material available at https://doi. org/10.1186/s12951-021-00893-6.

Additional file 1. Additional figures.

\section{Acknowledgements}

Not applicable.

\section{Authors' contributions}

$\mathrm{PL}, J \mathrm{D}, \mathrm{YL}$ and $\mathrm{WZ}$ designed and conceptualized this study. PL, YZ, SH and XS performed the in vitro and in vivo experiments. PL, YY, YP QL and SH drafted the manuscript. All authors read and approved the final manuscript.

\section{Funding}

This work was supported by Innovation-Driven Project of Central South University (No. 20170030010004), National Natural Science Foundation of China (No. 21804144, U1903125, 82073799), and Hunan Provincial Clinical Medical Technology Innovation Guidance Project (2020SK50501).

Availability of data and materials

All data generated or analysed during this study are included in this published article.

\section{Declarations}

Ethics approval and consent to participate

No applicable. 


\section{Consent for publication}

All authors agree to be published.

\section{Competing interest}

The authors declare no conflict of interest.

\section{Author details}

'Xiangya School of Pharmaceutical Sciences, Central South University, Changsha 410013, Hunan, China. ${ }^{2}$ Department of Pediatric Surgery, Hunan Children's Hospital, Changsha 410004, Hunan, China. ${ }^{3}$ Department of General Surgery, Peking Union Medical College Hospital, Beijing 100730, China.

Received: 10 February 2021 Accepted: 11 May 2021

Published online: 21 May 2021

\section{References}

1. Dolmans D, Fukumura D, Jain RK. Photodynamic therapy for cancer. Nat Rev Cancer. 2003;3:380-7.

2. Li X, Kwon N, Guo T, Liu Z, Yoon J. Innovative strategies for hypoxic-tumor photodynamic therapy. Angew Chem Int Edit. 2018;57:11522-31.

3. Xu J, Yu S, Wang X, Qian Y, Wu W, Zhang S, Zheng B, Wei G, Gao S, Cao Z, Fu W, Xiao Z, Lu W. High affinity of chlorin e6 to immunoglobulin g for Intraoperative fluorescence image-guided cancer photodynamic and checkpoint blockade therapy. ACS Nano. 2019;13:10242-60.

4. Fan W, Huang P, Chen X. Overcoming the Achilles' heel of photodynamic therapy. Nat Rev Cancer. 2016:45:6488-519.

5. Wang T, Wang D, Yu H, Wang M, Liu J, Feng B, Zhou F, Yin Q, Zhang Z, Huang Y, Li Y. Intracellularly acid-switchable multifunctional micelles for combinational photo/chemotherapy of the drug-resistant tumor. ACS Nano. 2016;10:3496-508.

6. Yu WQ, He XQ, Yang ZH, Yang XT, Xiao W, Liu R, Xie R, Qin L, Gao HL. Sequentially responsive biomimetic nanoparticles with optimal size in combination with checkpoint blockade for cascade synergetic treatment of breast cancer and lung metastasis. Biomaterials. 2019;217:119309.

7. Akhavan O, Ghaderi E, Aghayee S, Fereydooni Y, Talebi A. The use of a glucose-reduced graphene oxide suspension for photothermal cancer therapy. J Mater Chem A. 2012;22:13773-81.

8. Mahmoudi K, Garvey KL, Bouras A, Cramer G, Stepp H, Raj JGJ, Bozec D, Busch TM, Hadjipanayis CG. 5-aminolevulinic acid photodynamic therapy for the treatment of high-grade gliomas. J Neuro-Oncol. 2019;141:595-607.

9. Alsaab HO, Alghamdi MS, Alotaibi AS, Alzhrani R, Alwuthaynani F, Althobaiti YS, Almalki AH, Sau S, lyer AK. Progress in clinical trials of photodynamic therapy for solid tumors and the role of nanomedicine. Cancers. 2020;12:2793.

10. Aniogo EC, George BPA, Abrahamse H. The role of photodynamic therapy on multidrug resistant breast cancer. Cancer Cell Int. 2019;19:91.

11. Liang C, Zhang XL, Yang MS, Wang WJ, Chen P, Dong XC. Remodeling tumor microenvironment by multifunctional nanoassemblies for enhanced photodynamic cancer therapy. ACS Mater Lett. 2020;2:1268-86.

12. Fan YT, Zhou TJ, Cui PF, He YJ, Chang X, Xing L, Jiang HL. Modulation of intracellular oxygen pressure by dual-drug nanoparticles to enhance photodynamic therapy. Adv Funct Mater. 2019;29:1806708.

13. Dang J, He H, Chen D, Yin L. Manipulating tumor hypoxia toward enhanced photodynamic therapy (PDT). Biomater Sci. 2017;5:1500-11.

14. Cheng $X$, He L, Xu J, Fang $Q$, Yang L, Xue Y, Wang X, Tang R. Oxygenproducing catalase-based prodrug nanoparticles overcoming resistance in hypoxia-mediated chemo-photodynamic therapy. Acta Biomater. 2020;112:234-49.

15. Liu P, Xie X, Shi X, Peng Y, Ding J, Zhou W. Oxygen-self-supplying and HIF$1 a$ inhibiting core-shell nano-system for hypoxia-resistant photodynamic therapy. ACS Appl Mater Inter. 2019;11:48261-70.

16. Zeng W, Liu P, Pan W, Singh SR, Wei Y. Hypoxia and hypoxia inducible factors in tumor metabolism. Cancer Lett. 2015;356:263-7.

17. Meng X, Deng J, Liu F, Guo T, Liu M, Dai P, Fan A, Wang Z, Zhao Y. Triggered all-active metal organic framework: ferroptosis machinery contributes to the apoptotic photodynamic antitumor therapy. Nano Lett. 2019;19:7866-76.
18. Fuchs-Tarlovsky V. Role of antioxidants in cancer therapy. Nutrition. 2013:29:15-21.

19. Chen G, Yang YY, Xu Q, Ling MJ, Lin HM, Ma W, Sun R, Xu YC, Liu XQ, Li N, Yu ZQ, Yu M. Self-amplification of tumor oxidative stress with degradable metallic complexes for synergistic cascade tumor therapy. Nano Lett. 2020;20:8141-50.

20. Thomas AP, Lee AJ, Palanikumar L, Jana B, Kim K, Kim S, Ok H, Seol J, Kim D, Kang BH, Ryu JH. Mitochondrial heat shock protein-guided photodynamic therapy. Chem Commun. 2019;55:12631-4.

21. Zhao L, Li J, Su Y, Yang L, Chen L, Qiang L, Wang Y, Xiang H, Tham HP, Peng J, Zhao Y. MTH1 inhibitor amplifies the lethality of reactive oxygen species to tumor in photodynamic therapy. Sci Adv. 2020. https://doi.org/10. 1126/sciadv.aaz0575.

22. Huo D, Jiang XQ, Hu Y. Recent advances in nanostrategies capable of overcoming biological barriers for tumor management. Adv Mater. 2020;32:1904337.

23. Han H, Hou Y, Chen X, Zhang P, Kang M, Jin Q, Ji J, Gao M. Metformininduced stromal depletion to enhance the penetration of gemcitabineloaded magnetic nanoparticles for pancreatic cancer targeted therapy. J Am Chem Soc. 2020;142:4944-54.

24. Cheng YH, Cheng H, Jiang CX, Qiu XF, Wang KK, Huan W, Yuan A, Wu JH, Hu YQ. Perfluorocarbon nanoparticles enhance reactive oxygen levels and tumour growth inhibition in photodynamic therapy. Nat Commun. 2015;6:1-8.

25. Liu P, Xie X, Liu M, Hu S, Ding J, Zhou W. A smart $\mathrm{MnO}_{2}$-doped graphene oxide nanosheet for enhanced chemo-photodynamic combinatorial therapy via simultaneous oxygenation and glutathione depletion. Acta Pharm Sin B. 2021;11:823-34.

26. Chen X, Liu Y, Wen Y, Yu Q, Liu J, Zhao Y, Liu J, Ye G. A photothermaltriggered nitric oxide nanogenerator combined with siRNA for precise therapy of osteoarthritis by suppressing macrophage inftammation. Nanoscale. 2019;11:6693-709.

27. Zhang Y-H, Qiu W-X, Zhang M, Zhang L, Zhang X-Z. MnO $\mathrm{O}_{2}$ motor: a prospective cancer-starving therapy promoter. ACS Appl Mater Inter. 2018;10:15030-9.

28. Lin L-S, Song J, Song L, Ke K, Liu Y, Zhou Z, Shen Z, Li J, Yang Z, Tang W, Niu G, Yang H-H, Chen X. Simultaneous fenton-like ion delivery and glutathione depletion by $\mathrm{MnO}_{2}$-based nanoagent to enhance chemodynamic therapy. Angew Chem Int Edit. 2018;57:4902-6.

29. Dong Z, Feng L, Chao Y, Hao Y, Chen M, Gong F, Han X, Zhang R, Cheng L, Liu Z. Amplification of tumor oxidative stresses with liposomal fenton catalyst and glutathione inhibitor for enhanced cancer chemotherapy and radiotherapy. Nano Lett. 2019;19:805-15.

30. Chen Z, Shi T, Zhang L, Zhu P, Deng M, Huang C, Hu T, Jiang L, Li J. Mammalian drug efflux transporters of the ATP binding cassette (ABC) family in multidrug resistance: A review of the past decade. Cancer Lett. 2016:370:153-64.

31. van Attikum H, Gasser SM. ATP-dependent chromatin remodeling and DNA double-strand break repair. Cell Cycle. 2005;4:1011-4.

32. Liu T, Liu W, Zhang M, Yu W, Gao F, Li C, Wang S-B, Feng J, Zhang X-Z. Ferrous-supply-regeneration nanoengineering for cancer-cell-specific ferroptosis in combination with imaging-guided photodynamic therapy. ACS Nano. 2018;12:12181-92.

33. Liu P, Liu X, Cheng Y, Zhong S, Shi X, Wang S, Liu M, Ding J, Zhou W. Coreshell nanosystems for self-activated drug-gene combinations against triple-negative breast cancer. ACS Appl Mater Inter. 2020;12:53654-64.

34. Liu P, Shi X, Zhong S, Peng Y, Qi Y, Ding J, Zhou W. Metal-phenolic networks for cancer theranostics. Biomater Sci. 2021. https://doi.org/10. 1039/d1030bm02064h.

35. Wu L, Zhang J, Watanabe W. Physical and chemical stability of drug nanoparticles. Adv Drug Del Rev. 2011;63:456-69.

36. Hu C, Cun X, Ruan S, Liu R, Xiao W, Yang X, Yang Y, Yang C, Gao H. Enzymetriggered size shrink and laser-enhanced $\mathrm{NO}$ release nanoparticles for deep tumor penetration and combination therapy. Biomaterials 2018;168:64-75.

37. Stone JR, Yang S. Hydrogen peroxide: a signaling messenger. Antioxid Redox Sign. 2006;8:243-70.

38. Ding B, Shao S, Jiang F, Dang P, Sun C, Huang S, Ma Pa, Jin D, Al Kheraif AA, Lin J. MnO2-disguised upconversion hybrid nanocomposite: an ideal architecture for tumor microenvironment-triggered $\mathrm{ucl} / \mathrm{mr}$ bioimaging and enhanced chemodynamic therapy. Chem Mater. 2019;31:2651-60. 
39. Wan S-S, Liu M-D, Cheng Q, Cheng H, Zhang X-Z. A mitochondria-driven metabolic sensing nanosystem for oxygen availability and energy blockade of cancer. Adv Ther. 2020;3:2000019.

40. Ren J, Zhang L, Zhang J, Zhang W, Cao Y, Xu Z, Cui H, Kang Y, Xue P. Lightactivated oxygen self-supplied starving therapy in near-infrared (NIR) window and adjuvant hyperthermia-induced tumor ablation with an augmented sensitivity. Biomaterials. 2020;234:119771

41. Wang H, Chao Y, Liu J, Zhu W, Wang G, Xu L, Liu Z. Photosensitizercrosslinked in-situ polymerization on catalase for tumor hypoxia modulation \& enhanced photodynamic therapy. Biomaterials. 2018;181:310-7.
42. Yang Z, Chen Q, Chen J, Dong Z, Zhang R, Liu J, Liu Z. Tumor-pH-responsive dissociable albumin-tamoxifen nanocomplexes enabling efficient tumor penetration and hypoxia relief for enhanced cancer photodynamic therapy. Small. 2018;14:1803262.

\section{Publisher's Note}

Springer Nature remains neutral with regard to jurisdictional claims in published maps and institutional affiliations.
Ready to submit your research? Choose BMC and benefit from:

- fast, convenient online submission

- thorough peer review by experienced researchers in your field

- rapid publication on acceptance

- support for research data, including large and complex data types

- gold Open Access which fosters wider collaboration and increased citations

- maximum visibility for your research: over $100 \mathrm{M}$ website views per year

At BMC, research is always in progress.

Learn more biomedcentral.com/submissions 